\title{
ILUMINANDO AS VIVÊNCIAS DE MULHERES PORTADORAS DE TRANS- TORNOS PSÍQUICOS E MORADORAS DE UMA RESIDÊNCIA TERAPÊUTICA
}

\section{ILLUMINATING THE EXPERIENCES OF WOMEN SUFFERING FROM PSYCHIC DISTURBANCES WHO LIVE IN A THERAPEUTIC RESIDENCE}

\section{ILUMINANDO LAS VIVENCIAS DE LAS MUJERES PORTADORAS DE TRASTORNOS PSÍQUICOS QUE VIVEN EN UNA RESIDENCIA TERAPÉUTICA}

\author{
Valdete Preve Pereira', Miriam Süsskind Borenstein ${ }^{2}$
}

\begin{abstract}
${ }^{1}$ Mestre. Enfermeira do Instituto de Psiquiatria de Santa Catarina.
${ }^{2}$ Doutora. Professora do Departamento e da Pós-Graduação em Enfermagem da Universidade Federal de Santa Catarina. Membro do Grupo de Pesquisa História da Enfermagem e Saúde.
\end{abstract}

PALAVRAS-CHAVE:

Enfermagem psiquiátrica.

Saúde mental.

Centros de reabilitação.

\section{KEYWORDS:}

Psychiatric nursing.

Mental health.

Rehabilitation centers.

PALABRAS CLAVE:

Enfermería psiquiátrica. Salud mental. Centros de rehabilitación.

RESUMO: Trata-se de estudo com abordagem qualitativa, cujo objetivo é refletir com mulheres portadoras de transtornos psíquicos, o vivenciar de seu cotidiano, identificando os significados e co-construindo possibilidades de "vir-a-ser mais" como cidadãs. O estudo foi desenvolvido com moradoras de uma Residência Terapêutica, vinculada ao Instituto de Psiquiatria de Santa Catarina, em São José/SC. A coleta dos dados efetivou-se concomitante à implementação do processo de cuidado, segundo a teoria de Parse. Na análise dos dados foram identificados os seguintes significados: convivendo com o transtorno psíquico; coconstituindo padrões de inter-relação com outros; convivendo com as dificuldades de enfrentamento e superação de limites; co-criando possibilidades de vir-a-ser em saúde, cidadania e qualidade de vida; e coconstruindo a Residência Terapêutica como espaço de reabilitação psicossocial. Concluiu-se que vivenciar este processo propiciou mudanças de perspectivas destas mulheres, contribuindo para a mobilização de transcendências, no sentido de "vir-a-ser mais" como ser humano.

\begin{abstract}
This is a qualitative study whose objective is to reflect upon the everyday life of women who are bearers of psychic disturbances by identifying the meanings of their existences and co-building increased opportunities for them to become citizens. The study was developed with residents of a Therapeutic Residence, linked to the Instituto de Psiquiatria de Santa Catarina, in São José/SC. The data collection was done while providing health care, according to the theory proposed by Parse. Based on the data analysis, the following meanings were identified: living together with psychic disturbances; co-constituting interrelation patterns with "others"; living together with facing and overcoming limits; co-creating possibilities for health, citizenship and quality of life; co-building the Therapeutic Residence as a space of psycho-social rehabilitation. It was concluded that living this whole process generated a change in perspective in those women, contributing to mobilize transcendencies, in the sense of allowing personal growth as a human being.
\end{abstract}

RESUMEN: Se trata de un estudio con abordaje cualitativo, cuyo objetivo fue reflexionar con las mujeres portadoras de trastornos psíquicos el proceso de vida en su cotidiano identificándose los significados, así como, reconstruyendo la posibilidad de venir a ser más como ciudadanas. El estudio fue desarrollado con dos moradoras de una Residencia Terapéutica, vinculado al Instituto de Psiquiatría del Estado de Santa Catarina, localizada en la ciudad de San José. El referencial teórico utilizado según la Teoría del "Tornarse Humano" de Rosemarie Rizzo Parse. La colecta de los datos fue a través del proceso de cuidado en la práctica. Para el análisis de los datos, fueron identificados los siguientes significados: conviviendo con el trastorno psíquico; reconstituyendo padrones de interrelación con los otros; conviviendo con las dificultades del enfrentamiento y la superación de los limítes; co-creando posibilidades de venir a ser para la salud, la ciudadanía y la calidad de vida; re-construyendo la Residencia Terapéutica como un espacio de rehabilitación psico-social. Se llega a la conclusión que, la vivencia de este proceso propició cambios, en las perspectivas de éstas mujeres, contribuyendo en la movilización de las trascendencias, en el sentido de "venir a ser más" como seres humanos.

Endereço:

Valdete Preve Pereira

Rua Eduardo Nader, 857

88085-350 - Bairro Bom Abrigo, Florianópolis, SC.

E-mail: detepreve@zipmail.com.br
Artigo original: Pesquisa

Recebido em: 15 de maio de 2004

Aprovação final: 30 de agosto de 2004

Texto Contexto Enferm 2004 Out-Dez; 13(4):527-34. 


\section{INTRODUÇÃO}

Após a Segunda Guerra Mundial, inúmeras transformações passaram a ocorrer no cenário mundial, inclusive relacionadas com assistência psiquiátrica até então instituída, concentrada basicamente em hospitais psiquiátricos. Além dos fatores políticos e sociais, há que se ressaltar algumas contribuições que favoreceram essas transformações, tais como a teoria psicanalítica de Freud, os conceitos da psiquiatria dinâmica, os avanços das ciências sociais e o advento dos psicofármacos ${ }^{1}$.

A assistência psiquiátrica, que estava centrada nos hospitais, passa a ser gradativamente substituída por outras alternativas de atendimento, como a criação de comunidades terapêuticas, na Inglaterra, a partir de 1942; a psicoterapia institucional criada por François Tosquelles, no hospital psiquiátrico de Saint Alban, na França, em 1942; a psiquiatria de setor, também de origem francesa; os centros comunitários nos Estados Unidos, a partir dos anos 60 e, finalmente, a desinstitucionalização, iniciada por Franco Basaglia, em Gorizia, na Itália, no final da década de $1960^{2}$.

No Brasil, a partir dos anos 70, verifica-se um movimento de críticas contundentes ao governo, em função das políticas oficiais de saúde no campo psiquiátrico. Esse movimento tem início quando os trabalhadores de saúde mental e de outros segmentos da sociedade civil denunciam a violência e o abandono a que estavam submetidos os pacientes e as precárias condições de "assistência" que lhe eram oferecidas nos hospitais psiquiátricos.

Nesse contexto de grandes discussões, nos vários segmentos, surge o movimento da Reforma Psiquiátrica Brasileira. Trata-se de um processo global de transformação do sistema psiquiátrico, tomando como horizonte a desconstrução do universo manicomial e a criação de uma rede de cuidados e de relações com a sociedade, com uma visão totalmente nova ${ }^{2}$.

Em Santa Catarina, o Hospital Colônia Sant' Ana (HCS), um macro-hospital psiquiátrico estatal, impulsionado pelas mudanças que vinham ocorrendo no país, começa a implementar algumas estratégias, no sentido de promover melhorias no atendimento de seus pacientes. Dentre elas, destaca-se o desenvolvimento de projetos de reabilitação psicossocial e de reinserção social, como a criação de Residências Terapêuticas ${ }^{3}$.

A Residência Terapêutica caracteriza-se por moradia ou casa, inserida de preferência na comunidade, destinada aos portadores de transtornos psíqui- cos, egressos de internações psiquiátricas de longa permanência, que não possuem suporte social e laços familiares que viabilizem sua inserção social ${ }^{4}$. Buscavase, dessa forma, oferecer a alguns dos pacientes internados há longo tempo na instituição e que haviam perdido o vínculo com seus familiares, a oportunidade de um viver de forma mais saudável e mais próximo da realidade de vida do indivíduo considerado "sadio".

Este projeto passou a funcionar em dezembro de 1990, em uma pequena casa, nas proximidades do hospital, com nove moradoras. Entretanto, apesar dos esforços na sua implantação e implementação, havia a necessidade de utilização de um referencial teórico que pudesse subsidiar o cuidado oferecido a estas moradoras, uma vez que somente as condições físicas, materiais e sociais eram insuficientes para possibilitar-lhes um cuidado mais humanizado. Havia a necessidade de um referencial que embasasse a prática de enfermagem, de modo que as moradoras fossem efetivamente cuidadas e que pudessem caminhar para atingir um completo bem-estar, conseguindo ir além, transcendendo as suas dificuldades. Até porque a proposta da Reforma Psiquiátrica significa ousar, ir além, buscar outras possibilidades para um "viver mais saudável".

Assim, a partir do conhecimento mais profundo da teoria "Tornar-se humano", de Rosemarie Rizzo Parse, percebeu-se a oportunidade de implementar uma abordagem mais efetiva com base nesse referencial teórico. A teoria de Parse está fundamentada em uma prática de Enfermagem inovadora, segundo a qual cabe à enfermeira, através da presença verdadeira, esclarecer significados nas situações do cotidiano das clientes, compartilhando com elas pensamentos e sentimentos; é um "estar com", e não um fazer pelas pessoas. Conforme essa teoria ${ }^{5}$, a saúde é um processo aberto de vir-a-ser, ritmicamente co-constituinte de inter-relação ser humano-ambiente, como um processo intersubjetivo de transcender os "possíveis" e de relacionar prioridades de valor; da mesma forma, o ser humano, por meio da compreensão dos significados de suas experiências de vida, é capaz de co-criar suas novas possibilidades de saúde e também de transcender as perspectivas, indo "além do que se é".

A teoria ${ }^{7}$ refere-se à qualidade de vida a partir da perspectiva da própria pessoa enquanto apropriação das experiências vividas, criando a vida pela interconexão humano-universo. Ressalta que a qualidade de vida não é o que as pessoas de fora da experiência vivida pensam que é, mas o que a pessoa vi- 
vendo a vida refere ser.

Desse modo, desenvolvemos este estudo, cujo objetivo foi refletir com mulheres portadoras de transtornos psíquicos, moradoras em uma Residência Terapêtica, o vivenciar seu cotidiano, co-construindo possibilidades de vir-a-ser em saúde e cidadania e qualidade de vida.

\section{METODOLOGIA}

Trata-se de uma pesquisa qualitativa do tipo convergente assistencial, na qual foi utilizada a abordagem metodológica da teoria "Tornar-se humano", que traz em seu teor as tendências atuais de valorização da pessoa como agente de sua saúde, responsável por si, e com o respeito incondicional ao homem como ser humano e à sua existência.

Participaram do estudo, duas mulheres portadoras de transtornos psíquicos, moradoras de uma Residência Terapêutica, que preencheram os critérios de seleção, ou seja: estar compensada psiquiatricamente, concordar em participar do estudo e ter disponibilidade de horário. As participantes que integraram o grupo de estudo foram orientadas sobre o consentimento livre esclarecido, que rege a ética nas pesquisas com seres humanos ${ }^{6}$. As participantes foram informadas sobre os cuidados éticos, e assinaram o protocolo de consentimento livre e esclarecido. Além disso, foi obtida, também, a autorização da instituição para a realização do estudo.

A prática assistencial foi realizada no ambiente da Residência Terapêutica, localizada próximo ao antigo hospital Colônia Sant' Ana, atual Instituto de Psiquiatria de Santa Catarina (IPq-SC), no município de São José/SC. Trata-se de um projeto de moradia fixa, vinculado ao Centro de Convivência Sant' Ana. As residentes, em número de nove no total, são acompanhadas semanalmente por uma equipe técnica do Hospital psiquiátrico, a qual é constituída por uma enfermeira, um psicólogo e uma assistente social. Uma das autoras é integrante desta equipe multidisciplinar. A coleta de dados ocorreu durante os seis encontros individuais realizados com cada uma das residentes, no período de 2 a 30 de outubro de 2002, e aconteceu por meio de diálogos, seguindo a linha fenomenológica.

A dinâmica do estudo deu-se através do processo de cuidado e seguiu as três dimensões da prática metodológica proposta pela teoria ${ }^{7}$ : 1) pela iluminação dos significados das vivências das participantes; 2) pela sincronização de ritmos que apareceu no proces- so de tratar do fluxo da cadência inter-humana; 3) pela mobilização de transcendência que se deu pelo processo de ir além do significado do momento, para as mudanças nos padrões de comportamento dessas mulheres.

Os encontros foram gravados em fita cassete e posteriormente foram transcritas. Além disso, foi utilizado um diário de campo com notas teóricas (NT), notas pessoais (NP), bem como, notas de reflexão (NR), acerca do tema pesquisado.

Para análise dos dados, foram utilizadas as duas etapas metodológicas propostas na teoria: a extração de síntese e a interpretação heurística. $\mathrm{Na}$ extração de síntese, foram levantados os dados que correspon-dem à síntese das essências das experiências vividas, descritas pelas participantes do estudo, criando-se, a partir desses dados, uma estrutura que possibilitasse a reflexão dos significados dessas vivências. A interpretação heurística deu-se através da interpretação dos significados, tal como percebidos e expostos pelas participantes no decorrer do processo, fazendo-se uma conexão com a estrutura da teoria, permitindo a percepção das transformações metodológicas e formando um conhecimento novo ${ }^{7}$.

\section{APRESENTAÇÃO DOS RESULTADOS}

Conforme o objetivo deste estudo e decorrente da análise dos dados dos encontros realizados, emergiram cinco significados: convivendo com o transtorno psíquico; co-constituindo padrões de inter-relação com "outros"; co-criando possibilidades de vir-a-ser em saúde, cidadania e qualidade de vida; co-construindo a Residência Terapêutica como espaço de reabilitação psicossocial.

\section{Convivendo com o transtorno psíquico}

Ser portador de transtorno psíquico constituise em uma experiência complexa, difícil, com reflexos de incapacidade, sofrimento, estigma, preconceitos, perda de possibilidades e limitações. Vários autores ${ }^{8-}$ 9 referem-se à doença mental como um estado de sofrimento, o sofrimento psíquico. Sofrer representa padecer, ser atormentado, experimentar uma sensação desagradável, às vezes insuportável; trata-se de uma experiência única, com significado diferente para cada pessoa. Neste estudo, esse sentimento é expresso pelas participantes em muitas de suas falas, como no depoimento: [...] quem olha de fora, a minha cabeça só vê este corte que tem aqui, que tá tudo saradinho, mas por 
dentro o miolo tá tudo muidinho, bem muidinho, até o médico já disse, já pensou, como é que eu posso fazer as coisas direito se a minha cabeça por dentro tá deste jeito?[...] (Flora).

Este sentimento é referido pelas participantes do estudo, ligado aos sintomas que incomodam, enfraquecem e confundem seus pensamentos, e é visualizado na fala:

[...] ia me dando uma tontura, um nervosismo, ficava tremendo, um sofrimento. Olha, eu tô melhor, mais de vez. em quanto tenho dor de cabeça forte e tontura, e o que mais me atrapalha mesmo é o esquecimento, eu esqueço de tudo, da hora, do horário de comê, de trabalhá, de tudo (Rosa).

Uma das participantes, ainda sem consciência clara da doença e de seu curso crônico, não consegue perceber a necessidade do uso contínuo dos medicamentos, então os interrompe e sofre com as recidivas dos sintomas, e relata:

[...] eu penso assim, vê se a senhora me entende: se eu for parando de tomar estes remédios devagarinho, um pouquinho cada vez, mas bem devagarinho, a doença nem vai sentir, ela vai acostumando, acostumando, e quando a gente vê, en estou curada, não preciso de mais nenbum remédio, vou tá boazinha[...] (Flora).

O portador de transtorno psíquico sente-se enfraquecido pelo uso de medicamentos que lhe impedem de controlar por si mesmo suas reações, tanto positivas quanto negativas, de afeto, comunicação e agressividade $^{10}$.

O sofrimento humano, segundo os pressupostos da teoria, pode ser construído através do processo humano-universo e pode estar ligado a outros valores, como perdas, tristezas, sonhos e visões de mun$\mathrm{do}^{11}$. As participantes deste estudo falam das perdas causadas pela doença, das perdas sociais (família e amigos), da perda dos conhecimentos adquiridos na infância que foram dissipados com o tempo, das perdas da autoconfiança, da autodeterminação e, principalmente, dos sonhos interrompidos.

[...] a senhora jápensou? Eu perdi tudo na vida, quando me deu aquela loucura na cabeça e eu saí da casa da minha patroa, en sabia tudo, sabia ler, escrever, até fazer conta, $e$ agora eu não sei fazer mais nada, perdi tudo (Flora).

Para essas mulheres, a experiência da doença trouxe sofrimento e deixou marcas que as acompanham no dia-a-dia; porém, dentro dos valores prioritários atribuídos por cada uma, elas vão fazendo suas escolhas, buscando possibilidades para ir além, apesar dos limites impostos pelo processo saúde-doença.

\section{Co-constituindo padrões de inter-relação com "outros"}

A autora ${ }^{12}$ entende o ser humano como unitário, e que, no processo de relação com o universo, está livre para estruturar suas experiências de vida. Afirma que o ser humano, ao longo de sua vida, co-cria padrões de relações com outras pessoas e com o ambiente, vivendo as unidades paradoxais de revelar-ocultar, capacitar-limitar e de conectar-separar.

Dentro da singularidade de cada ser, essas mulheres vivem tais unidades paradoxais de relação, ora representadas por oportunidades e limitações, ora expressando ritmos de envolvimento e não-envolvimento, aproximação e distanciamento, conforme a fala:

[...] em geral o nosso relacionamento é bom, mais eu me dou melhor com a Maria, porque ela é muito boazinha, me ajuda e reparte as coisas comigo, mais tem uma que en não me dou tão bem, como a Margarida, a Tereza, a Zilda e a Lucí, porque elas são muito reclamonas. Reclamam de tudo que é coisa, que eu não faço o serviço direito, mais é que eu não enxergo direito, aí às vezes a comida não fica muito boa [...] (Rosa).

As participantes deste estudo coexistem no cotidiano de suas experiências e co-constituem uma forte relação interpessoal com as demais companheiras da Residência Terapêutica; porém, não reconhecem esta ligação como experiência em família. Para elas, família ainda é constituída por pessoas da mesma consangüinidade, conforme o relato de uma delas:

[...] nóis moramo juntas aqui, né, a gente se entende bem, mais não é família, pai, irmão, irmã, e de veź em quando é aquele lero-lero. Tem uma guria que tá querendo vir prá cá, uma tal de Salete, acho melhó ficá só quem tá aqui, senão é um tal de fuxico prá cá, fuxico pra lá, aquela coisa, e nóis vamos acabar tudo na rua [...] (Flora).

Embora as participantes não se percebam como família, parece-nos, no entanto, que este conceito está ligado somente a questões de nomenclatura, pois em suas falas fica evidente a inter-relação que permeia a co-constituição do grupo de moradoras, baseado em um forte sistema de auto-ajuda, e na identificação de "papéis", muito semelhantes daqueles encontrados nos modelos tradicionais de família. Além das relações coconstituídas pelas moradoras da Residência Terapêutica entre si, elas também estabeleceram relações com os vizinhos, com comerciantes da vila e com o pároco, e ainda mantiveram as relações com os funcionários e demais integrantes do HCS, atual IPq.

Em suas falas percebemos a preocupação e o 
cuidado de umas com as outras, quando saem de casa e não avisam, quando se ajudam nas tarefas domésticas ou se preocupam com a manutenção, segurança e provimento das necessidades da casa, cada uma assumindo um tipo de papel: de pai, ou mãe, ou irmãs. A fala seguinte evidencia a preocupação e o cuidado que cada uma tem com a outra:

eu me preocupo sim, essa pessoa por aí, sem cabeça, caminhando, a gente se sente responsável por ela, se acontecer alguma coisa a gente se sente responsável por ela, agora que tem muito movimento nestas ruas, essa menina solta por aí (Flora).

As mulheres deste estudo, dentro deste processo vivencial, têm buscado e conseguido co-constituir novos relacionamentos, enriquecendo o seu círculo de relações sociais, demonstrando claramente que têm conseguido avançar no sentido amplo das relações sociais.

\section{Convivendo com dificuldades de enfrenta- mento e superação de limites}

Alguns autores ${ }^{13-4}$ referem que o portador de transtorno psíquico grave, de longa duração, apresenta limitações em sua vida; encontra-se socialmente em desvantagem, possui um valor negativo. Seu poder de contrato costuma ser anulado, pois o entendimento é de que os bens dos loucos tornam-se suspeitos, suas mensagens incompreensíveis e seus afetos desnaturados.

Assim, podemos perceber como é difícil para o portador de transtorno psíquico enfrentar as situações adversas que se apresentam em seu cotidiano, e o grande esforço que necessita fazer, para superar as limitações impostas por sua doença e por sua condição de doente.

As mulheres deste estudo indicam inúmeras situações que vão constituindo suas experiências vividas, cujo enfrentamento é muito difícil, ou quase impossível, como, por exemplo, abordar os vizinhos proprietários dos animais que invadem e ficam soltos no quintal da residência. Esses animais costumam danificar todas as plantas cultivadas pelas moradoras. Elas referem que fica muito difícil abordar autoridades quanto à segurança da casa, quando crianças e adolescentes não respeitam a residência e jogam pedras, tirando o sossego das mulheres que ali habitam. Essas situações incomodam as participantes do estudo assim como as outras moradoras da Residência Terapêutica, porém, elas preferem passar a responsabilidade da solução para os funcionários do hospital, pois ainda não se sentem seguras o suficiente para o seu enfrentamento, como podemos identificar nesta fala:

[...]não dá para fazer a plantação por causa das criações dos vizinhos que invadem o quintal, são as galinhas que ciscam tudo, comem as folhas, não deixam nada vivo. É a senhora que tem o direito de dar segurança. Nós moramos aqui, mas o direito de dar segurança é seu. Hoje a dona Tereza quer uma folbinhas de couve, e não tem (Flora).

Além dos aspectos já relacionados, as mulheres referem sentir necessidade de sair para comprar suas roupas, calçados e outras coisas indispensáveis para o funcionamento da casa, porém dizem não ter coragem e autonomia para transitar pelo centro da cidade sozinhas, usar transporte coletivo, ou lidar com dinheiro, como no depoimento: [...] e também não sei comprá, só se alguém me ajudá, eu não posso andar por ai sozinha, só acompanhada, só consigo ir sozinha daqui pro hospital, do hospital prá casa. Olha, eu não posso ir assim sozinha, preciso ir com uma pessoa inteligente que saiba comparar o preço das coisas, e quanto dinheiro, né [...](Flora).

Neste momento, o movimento, no sentido de ir além, de enfrentamento e superação dos limites, pode ser lento e, neste caso, quase sempre se torna necessário o apoio profissional, norteado por referenciais adequados e efetivos. A enfermeira, por meio de seu conhecimento e de sua presença verdadeira, pode coconstituir e iluminar os significados das experiências vividas por elas e, através do processo reflexivo e da interpretação dessas experiências, motivá-las para enfrentar e superar os limites que se apresentam ${ }^{15}$.

\section{Co-criando possibilidades de vir-a-ser em saú- de, cidadania e qualidade de vida}

O homem estrutura os significados das experiências vividas e co-cria padrões de relação rítmicos com outros e com o ambiente, movendo-se do que não é para o que é, buscando co-transcender às dificuldades encontradas, em um processo de mudança e de transformação. Mudança, no sentido de ir além, com a presença de uma força energizante que origina e gera maneiras únicas de viver. Mudança como um processo contínuo de inter-relação homem-ambiente, reconhecido pela sua diversidade, pela qual um padrão é ao mesmo tempo igual e diferente. Neste mover-se, a coragem, a esperança e os sonhos encontram seu lugar e, dentro dos ritmos de cada um, possibilitando um vir-a-ser, no sentido de sua cotranscendência, para ser mais ${ }^{12}$.

As mulheres deste estudo vivenciam em seu co- 
tidiano este processo de transformação, processo que se caracteriza por ser difícil, sofrido e carregado de limitações e enfrentamentos, mas que elas vêm co-criando possibilidades de ir além, de transcender. Foi possível perceber esse fato, quando uma das mulheres resolveu assumir sozinha seu tratamento, em decorrência das perdas que vinha sofrendo com a negação do problema:

[...] a senhora sabe daquele assunto do meu remédio, a senhora disse que eu pensasse, pois é, é bom mesmo en tomar esses remédios aqui, ia ser melhor prá mim, não precisava ir todo dia de manhã, de tarde e a noite no hospital prá tomá, ia ser muito bom de agora em diante vou toma aqui [...] (Flora).

As participantes sinalizaram também, em suas falas, alguns aspectos referentes às suas vivências como cidadãs, sujeitos de direito. Direito de ter um bom atendimento, de possuir documentos, de ter uma aposentadoria, como possibilidade de trocas sociais e, principalmente, de fazer valer seus direitos como cidadãs na sociedade em que vivem.

Ressalta-se a necessidade de pensar novas idéias, de produzir novos vocábulos e novas práticas subjetivas, que são indispensáveis para produzir uma sociedade mais justa e tolerante, onde a noção de cidadania implique não apenas o reconhecimento de direitos ou proteção de singularidade, mas um processo ativo de ampliação da capacidade de todos e de cada um em especial ${ }^{16}$. Segundo o mesmo autor, é importante que as pessoas com transtorno psíquico possam agir de modo livre e participativo e, portanto, que a loucura não implique impossibilidade.

Durante o processo deste estudo, tentando compreender os significados das vivências destas mulheres, ficou evidente o sentimento de satisfação que elas possuem em relação a si mesmas e em relação à sua vida cotidiana. Dentro da simplicidade do seu viver, percebem-se vivenciando momentos de realização, sonhos e felicidade, conforme o depoimento:

[...] sabe, eu tive pensando, a gente tem conversado estes dias e eu tenho pensado muito nas coisas, e veio uma idéia que eu tenho há muito tempo na minha cabeça, sabe, é que eu queria muito voltar a estudar, já pensou, tudo aquilo que eu desaprendi, podia lembrar de novo [...] (Flora).

Qualidade de vida implica perceber que os seus objetivos e desejos foram adequadamente satisfeitos. É o resultado, portanto, das condições subjetivas de um indivíduo nos vários aspectos que compõem sua vida, como: seu trabalho, sua vida social, sua saúde física e seu estado emocional ${ }^{17}$. $\mathrm{Na}$ teoria do "Tornar- se humano", a qualidade de vida é entendida a partir da perspectiva da pessoa; não é o que as pessoas de fora da experiência vivida pensam que é, mas o que a pessoa vivendo a vida refere ${ }^{15}$.

\section{Co-construindo a "Residência Terapêutica" como espaço de reabilitação psicossocial}

A vivência na Residência Terapêutica tem oportunizado a estas moradoras uma riqueza de experiências e tem contribuído significativamente para o ir além, passando do que não é para o que é, desde a execução das tarefas domésticas, onde são exercitadas as habilidades pessoais - lavar, passar, cozinhar, vestir-se e autocuidar-se - e valores como: responsabilidade, iniciativa, senso crítico, confiança, segurança, comprometimento, companheirismo, ajuda mútua e resgate de identidade, segundo a fala de uma das participantes:

[...] eu não posso ir, porque en tenho que cuidar da casa, alguém tem que cuidar das frutinha, senão a gurizada rouba. E demais tem casa prá limpá, roupa prá lavá, tem que fazê comida (Flora).

A importância do trabalho no processo de reabilitação psicossocial é fundamental, pois trabalhar aumenta a satisfação e a auto-estima dos usuários e interrompe o ciclo de pobreza e dependência; além disso, o trabalho cria oportunidades de socialização e de comunicação ${ }^{18}$. Neste aspecto, a Residência Terapêutica tem, também, oportunizado possibilidades de reabilitação e de ir além, tanto no seu espaço interno, no movimento do seu cotidiano, como também em favorecer e permitir que suas moradoras possam se engajar em atividades externas.

Uma das participantes prefere trabalhar no ambiente doméstico e, em suas falas, expressa freqüentemente o grande valor que atribui ao trabalho. Realiza atividades nos cuidados da casa e da horta, faz planos para a ampliação de seu trabalho ligado à agricultura, o que inclusive a impulsiona para novas relações sociais com vizinhos e funcionários. Ela relata:

[...] eu fui lá, e falei com aquele moço que a senhora falou, e ele vai arrumar as coisas e vem aqui fazer a cerca, $e$ dai eu vou poder fazer a plantação que tanto quero. E tem outra coisa também, já comecei a tomar meus remédios aqui, olha, tô tomando bem direitinho, fica bem mais fácil, não preciso sair de casa [...] (Flora).

É neste espaço da Residência Terapêutica que participantes encontraram lugar para sua subjetividade e privacidade, seja na forma de guardar seus pertences, de dar significado para cada peça de roupa, de 
contar sua história através delas, de acalentar seus sonhos para voltar a estudar e de aumentar sua autoestima cuidando de sua aparência, almejando usar roupas e sapatos novos, ou preparando uma comidinha caprichada para festejar o Natal que, em sua concepção, é uma festa de Paz. E expressa nesta fala:

[...] a senhora sabe que ainda não deu de comprá a minha roupinha e o meu sapatinho pro Natal, mas eu já botei o meu nome prá ir no centro e eu não esqueço daquilo que a gente falou que eu posso voltar a estudar (Flora).

A Residência Terapêutica traz consigo experiências concretas e complexas do uso do tempo e espaço, com ritmos domésticos e afetivos, centrados nas demandas singulares de cada $u^{19}{ }^{19}$. É nesse sentido que a Residência Terapêutica vem-se constituindo como um espaço singular e apropriado, onde mulheres com transtornos psíquicos podem reconstruir suas vidas, como seres humanos únicos que trazem consigo suas crenças, valores, cultura, sendo capazes de transformar-se e construir sua própria história-ser, por meio das experiências vividas.

É aqui, na Residência Terapêutica, que essas mulheres estão podendo sonhar. Sonhar com o futuro e com uma vida melhor! Porque as possibilidades estão aí, abertas num vir-a-ser.

\section{CONSIDERAÇÕES FINAIS}

Neste momento, a psiquiatria vive um período de grandes transformações, quase de turbulência; as mudanças estão sendo projetadas, tanto no campo do pensamento quanto nas atitudes. Está-se colocando em xeque todo um paradigma construído e praticado durante séculos, - a forma de como lidar com a "loucura". É evidente que este movimento não se deu isoladamente, por si só, mas está, sim, condicionado e influenciado por todo um movimento social pós-guerra que suscitou no homem a reflexão sobre seus valores e novas formas de ser e estar no mundo.

O estudo permitiu vivenciar um novo momento profissional, fundamentado em um referencial teórico que possibilitou um olhar diferente à mulher portadora de transtorno psíquico, inserida em um programa de Residência Terapêutica, trazendo melhor compreensão do mundo em volta, contribuindo para a descoberta de novos significados, reflexões e validações.

Esta experiência coloca o enfermeiro face a face com inúmeros desafios. No início, pelas dificuldades de aplicação do processo, por ser um método novo, aberto e com uma linguagem diferente e complexa.
Porém, o maior desafio foi o de nortear a prática por um referencial totalmente diferente daquele aprendido na formação acadêmica e presente na prática profissional, com metas deterministas, prescritivas, voltadas para o controle e a predição do comportamento humano, inserido no paradigma da totalidade. Não raros foram os momentos em que estiveram presentes a tendência a julgamentos e a dificuldade de aceitar as diferenças, os ritmos e os limites das pessoas envolvidas no estudo.

Para o enfermeiro, inserido nesta prática de coconstituição e coexistência, aparecem, no início, sentimentos de ansiedade, insegurança e até de incapacidade que aos poucos transformam-se em envolvimento, respeito e co-transcendência. A participação do profissional enfermeiro, nesta prática, orientado pela teoria de Parse ${ }^{15}$, é um aspecto de destaque, por meio da "presença verdadeira com os outros", do "estar com"; trata-se de uma presença atentiva, que vai iluminando os significados das experiências vividas por estas mulheres, respeitando o ritmo e o mover-se individual de cada uma no sentido de "vir-a-ser", e "ser mais".

O desenvolvimento e a avaliação do processo de cuidado foram possíveis pela participação e receptividade destas mulheres no estudo. Os momentos de coexistência foram-se tornando fortes, baseados em sentimento de confiança e facilitaram a sua realização. No decorrer do processo, as moradoras mostraram-se confiantes para compartilhar suas experiências, emoções e sentimentos, como também dificuldades de caminhar em direção ao "ser mais". O envolvimento das moradoras nesta prática traduziu sonhos, desejos, e medos relacionados com o enfrentamento da doença, do relacionamento com outras companheiras e pessoas da comunidade, refletindo sobre o futuro e sobre possibilidades de "tornar-se mais".

Avaliando a aplicação da teoria "Tornar-se humano", de Parse, no cuidado com mulheres portadoras de transtorno psíquico, moradoras de uma Residência Terapêutica, foi possível perceber que a teoria é bem estruturada, sustentou adequadamente a prática, mostrou-se resolutiva, permitindo conhecer melhor o ser humano, respeitando suas necessidades, limites e escolhas, criando espaço para reflexão e possibilitando transformações no processo de vida dessas pessoas.

Dessa forma, entendo que os objetivos deste estudo foram alcançados, pois ele permitiu, por meio da co-constituição das relações e da coexistência situ- 
ada, identificar os significados que emergiram das vivências destas mulheres. Além disso, a compreensão desses significados permitiu a iluminação de vivências, oportunizando a superação de dificuldades e possibilitando o "tornar-se mais" como cidadãs moradoras de uma Residência Terapêutica.

\section{REFERÊNCIAS}

1 Scatena MCM. Saindo do hospital psiquiátrico: análise da inserção dos pacientes nos lares protegidos [tese]. Ribeirão Preto (SP): Departamento de Enfermagem Psiquiátrica e Ciências Humanas/ USP; 2000.

2 Aguiar MGG. Movimentos de saúde mental: trajetória e futuro. Anais do $47^{\circ}$ Congresso Brasileiro de Enfermagem; 1995 Nov19-24; Goiânia, Brasil. Goiânia: Ed. Da UFG; 1995.

3 Costa E, Borenstein MS. Problematizando para humanizar: uma proposta de transformação do cuidado em uma enfermaria psiquiátrica.Texto Contexto Enferm 2002;13(1):163-70.

4 Brasil. Portaria n.106, de 11 de fevereiro de 2000. Dispõe sobre os serviços residenciais terapêuticos. Diário Oficial da República Federativa do Brasil, 14 Fev 2000. N.31-E.

5 Parse RR. Illuminations: the human becoming theory in practice and research. New York: National League for Nursing; 1995.

6 Conselho Nacional de Saúde (BR). Resolução n.196, de 10 de outubro de 1996. Dispõe sobre as diretrizes e normas reguladoras de pesquisa envolvendo seres humanos. Brasília: O Conselho; 1996.

7 Parse RR. Nursing science: major paradigms, theories and critiques. Canadá: W.B. Saunders; 1987.

8 Rotelli F, Amarante P. Reformas psiquiátricas na Itália e no Brasil: aspectos históricos e metodológicos. In: Bezerra JB, Amarante P, organizadores. Psiquiatria sem hospício: contribuições ao estudo da reforma psiquiátrica. Rio de
Janeiro: Relume-Dumará; 1992. p. 41-55.

9 Hirdes A. Centro comunitário de saúde mental de São Lourenço do Sul: resgatando possibilidades de reabilitação psicossocial [dissertação]. Florianópolis (SC): Programa de Pós-Graduação em Enfermagem/UFSC; 1999.

10 Furegato RFF. Relações interpessoais terapêuticas na enfermagem. Ribeirão Preto: Scala; 1999.

11 Daly J. The lived experience of suffeg. In: Parse RR. Illuminattions: the becoming theory in practice and research. New York: NLN; 1995.p.243-68.

12 Parse RR. Man -living-health. New York: National League for Nursing; 1981.

13 Figueiredo Júnior MM. Esquizofrenia e reabilitação psicossocial: perspectivas teóricas e práticas [dissertação]. São Paulo (SP): Universidade de São Paulo; 1996.

14 Kinoshita RT. Contratualidade e reabilitação psicossocial. In: Pitta A . Reabilitação psicossocial no Brasil. São Paulo: Hucitec; 1996. p.55-9.

15 Parse RR. Quality of life: sciencing and living the art of human becoming. Nurs Sci Q 1994; 7(1):16-21.

16 Bezerra BJ. Cidadania e loucura: um paradoxo? In: Bezerra BJ, Amarante P, organizadores. Psiquiatria se hospício: contribuições ao estudo da reforma psiquiátrica. Rio de Janeiro: Relume: Dumará; 1992. p.113-26.

17 Roeder MA. Atividade física, saúde mental \& qualidade de vida. Rio de Janeiro: Shape; 2003.

18 Bertolote JM. Reabilitação psicossocial: a favor de um consenso. Geneva:WHO;1997. Mimeografado.

19 Pitta A. O que é reabilitação psicossocial no Brasil, hoje? In: Pitta A. Reabilitação psicossocial no Brasil. São Paulo: Hucitec; 1996. p.19-21. 